\title{
Amazonia boliviana: arqueología de los Llanos de Mojos.
}

\author{
Horacio Adolfo CALANDRA ${ }^{1}$, Susana Alicia SALCEDA ${ }^{2}$
}

\section{RESUMO}

A arqueologia da Amazônia boliviana ou das "Terras Baixas" compreende um imenso território que mostra, a luz da informação disponível, significativas descontinuidades espaço-temporais. A identificação nesta área de sociedades constituindo "cacicados da floresta tropical" a partir de critérios baseados em preconceitos, requer a reavaliação da préhistória regional do ponto de vista causal. A arqueologia beniana (de Llanos de Mojos) é conhecida, fundamentalmente, a partir das escavações de Erland Nordenskiöld, que sem dúvida estabeleceu as bases conceituais existentes atualmente. Entre os anos de 1977 e 1981 uma missão do Museu de La Plata (Argentina), sob a direção de B. Dougherty, e em estreita colaboração com o Instituto de Arqueologia de La Paz (Bolívia) e com o Amazonian Ecosystem Research (EUA), conduziu pesquisas sistemáticas considerando variados itens antropológicos e produzindo numerosas datações de radiocarbono. Estas contribuições ajudaram a esclarecer, mas não a simplificar o panorama pré-hispânico regional, tão importante na temática arqueológica sul-americana. Complementa este artigo uma exaustiva lista de bibliografias que facilita o acesso ao conhecimento sobre este grande território.

PALAVRAS CHAVE

Bolívia, Beni, Llanos de Mojos, Arqueologia, Aterros

\section{Bolivian Amazonia: archaeology of the Llanos de Mojos.}

\begin{abstract}
The archaeology of the Bolivian Amazonia or "Low lands" comprises a large territory that shows, significant time and spatial discontinuities. The identification of societies in this area constituting "Jefaturas de la Floresta Tropical", from criteria based on preconceptions requires the reassessment of regional prehistory from the causal point of view. Benian archeology (Llanos de Mojos) is fundamentally known, from the Erland Nordenskiöld excavations, which undoubtedly sets the conceptual bases existing to date. Between 1977 and 1981 a Mission of Museo de La Plata (Argentina), under the direction of B. Dougherty together with the Instituto Nacional de Arqueología of La Paz (Bolivia) and the Amazonian Ecosystem Research (EEUU), carried out systemic researches considering several anthropologic items and producing numerous radiocarbon datings. Such contribution helped to clarify, but not to simplify, the regional pre-Hispanic outlook, very important in the South American archeological thematic. An exhaustive bibliographic list that facilitates the access to the knowledge of that large area complements this presentation.
\end{abstract}

\section{KEY WORDS}

Bolivia, Beni, Plains of Mojos, Archaeology, Earth works

\section{INTRODUCCIÓN}

Recientemente y en oportunidad del centenario de la Misión Sueca Chaco-Cordillera se convocó a una reunión científica evocativa con el objeto de, desde el análisis de los datos proporcionados por aquellos precursores y lo elaborado con posterioridad y hasta la fecha, establecer el estado actual del conocimiento antropológico regional desde las distintas disciplinas concurrentes (Seminario Internacional "Un país más allá de las nubes", Jujuy 2001).

En la década del 80', fundamentalmente desde la arqueología y a partir de nuestros trabajos en la Amazonia Boliviana, tendientes a dilucidar las incógnitas respecto de su desarrollo cultural pre y post colonial y propiciando la ejecución de investigaciones arqueológicas complementarias en territorios circundantes (Dougherty y Calandra, 1984-85),

\footnotetext{
${ }^{1}$ Investigador CONICET. Facultad de Ciencias Naturales y Museo. Universidad Nacional de La Plata. Paseo del Bosque s/n (1900) La Plata. Argentina. TE: 542214257744 . E-mail: calandra@museo.fcnym.unlp.edu.ar

${ }^{2}$ Profesor Titular. Investigador CONICET. Facultad de Ciencias Naturales y Museo. Universidad Nacional de La Plata. Paseo del Bosque s/n (1900) La Plata, Argentina. TE: 54221 4257744. E-mail: ssalceda@museo.fcnym.unlp.edu.ar
} 
pusimos en marcha un proyecto en el cual el Chaco Meridional Sudamericano constituyó uno de sus objetivos (Calandra y Dougherty, 1991). A partir de entonces, con regularidad y en acuerdo con el CHACO (Centro del Hombre Antiguo Chaqueño), se realizaron estudios individuales que culminaron en la conformación de un grupo de trabajo que integra a distintas disciplinas del quehacer antropológico. Las investigaciones que efectuáramos en los últimos años en el marco de este proyecto dirigido a reconstruir la secuencia bio-cultural del Gran Chaco Meridional (Braunstein et al., 2002), han llevado a establecer relaciones con su entorno que abren una perspectiva vinculante alentadora para la ejecución de investigaciones sistemáticas recíprocas. Tal el caso del territorio boliviano pedemontano que, para quienes lo miramos desde el sur en función de los más recientes hallazgos en territorio de los valles mesotérmicos, con cronologías más antiguas que las reconocidas hasta no hace mucho tiempo para el sustrato cerámico (Pereira Herrera y Brockington, 2000), tal vez represente un ámbito generador nexo entre el Beni y el Gran Norte argentino.

La presente contribución es una actualización de la problemática de la arqueología beniana, basada fundamentalmente en los trabajos de campo y gabinete que Bernardo Dougherty ${ }^{3}$ condujera y permite destacar la total vigencia de la información obtenida por aquella Misión Arqueológica del Museo de La Plata a Mojos (Ver Apéndice: Sitios arqueológicos prospectados y/o excavados). Seguramente en el futuro las apreciaciones e interrogantes surgidos en esta realización conjuntamente con los aportes regionales de otros autores durante los últimos 10 años, casi exclusivamente referidos a las denominadas "obras de tierra", fundamenten la necesidad de encarar nuevas investigaciones en la Amazonia Boliviana, sujeta hoy a dispares consideraciones cuando se vislumbra la posibilidad de establecer nexos entre las tierras bajas y altas. Sirva como ejemplo la detección a partir de una arqueología del paisaje de caminos de filiación incaica que se internan desde las tierras altas al ámbito selvático (Raffino, com. per., 2002).

\section{Antecedentes}

Los Llanos de Mojos, extensa región del territorio boliviano, fue profusamente recorrida por los primeros españoles que penetraron hacia regiones "del interior" rumbo a lo desconocido, en busca de "El Dorado". Entre los numerosos expedicionarios que, en los inicios del período colonial, accedieron a este territorio pueden mencionarse: Anzúres en 1536, Aleman en 1564, Alvarez Maldonado en 1567, Suárez de Figueroa que en 1580 parte desde Santa Cruz hacia Mojos y Gonzalo de Solíz Holguín, quien en 1620/ 23 ingresa como conquistador del territorio beniano.

Durante el siglo XVII comienza la campaña evangelizadora en la zona. En 1603, el padre Bolívar logra penetrar hasta el punto de confluencia de los ríos Beni y
Madre de Dios. Con posterioridad otros religiosos como Cárdenas y Rehus (1621) llegan hasta los Llanos, siendo muerto este último a manos de los indígenas. El padre Cipriano Barace, en 1686, funda a orillas del Mamoré la Santísima Trinidad y lega a la posteridad interesantes relatos escritos. Años después, en 1689, el Padre Marbán, Superior de la zona de Mojos, realiza una importante contribución respecto de la historia misional regional. En este mismo año, el Padre Orellana, funda la Misión San Ignacio de Moxos. A partir de esta fecha, se suceden continuas fundaciones misionales, San Francisco Javier y San José en 1691 y San Borja en 1693, todas jesuíticas.

La rica información provista por estos pioneros marca la presencia en los Llanos de Mojos, para fines del siglo XVII, de diversos grupos aborígenes mostrando heterogeneidad lingüística y cultural. Aspectos comunes entre ellos fueron su preferencia por asentamientos en lugares elevados, y por lo tanto libres de inundaciones, y una subsistencia similar a la registrada para las poblaciones de la Floresta Tropical (Steward y Faron, 1959). De algunos de estos grupos existen referencias respecto de su filiación lingüística. Noble (1965) incluye dentro del Área Boliviana del Grupo Sur del Tronco Maipure a los Moxo y los cita como equivalentes a los Bauré, comparando los pares de cognatos entre diversas lenguas Arawak. Los Cayuvava, según Greenberg (1956), fueron agrupados junto a los Chapacura del sureste del Beni, como Arawak de la Subfamilia Ecuatorial; a este respecto Métraux (1946) los vincula a Movima y Canichana, como familias independientes (Dougherty y Calandra, 1984).

\section{El ambiente}

Los Llanos de Mojos abarcan una superficie de $110.000 \mathrm{~km}^{2}$. Se encuentran delimitados al oeste por los Andes, al norte por un tramo de los ríos Acre y Abuná, al este por los ríos San Miguel, Iténez (Guaporé) y Mamoré y al sur por el paralelo de $17^{\circ} 30^{\prime}$. Se extienden de sur a norte con una ligera inclinación presentando alturas máximas que varían entre los 450 y los 290 m.s.n.m. El Mamoré es el principal curso de agua, desemboca en el Iténez y éste, a su vez, en el Madeira, con un recorrido de $1500 \mathrm{~km}$ y un gradiente total de $170 \mathrm{~m}$. En general los ríos del Beni, todos pertenecientes al sistema Amazónico, en sus tramos inferiores irrumpen en un sector de barreras rocosas a las que vencen mediante las denominadas cachuelas, también conocidas como rápidos o saltos. La escasa pendiente y la dureza de las formaciones rocosas septentrionales, determinan la conformación de una enorme represa natural en el estío y por lo tanto un escurrimiento muy lento de las aguas represadas hacia el Madeira y una alta evaporación. Las características edafológicas, el escurrimiento lento y la gran evaporación son factores determinantes de inundaciones anuales prolongadas.

\footnotetext{
${ }^{3}$ Sin adjudicar al juicio crítico del Dr. Dougherty la responsabilidad de las inferencias realizadas en este trabajo, sus autores lo consideran como autor senior.
} 


\section{ACTA \\ AMAZONICA}

El tiempo de mayores precipitaciones es de noviembre a marzo. Las inundaciones comienzan a registrarse a fines de diciembre, alcanzan su punto culminante en febrero y descienden hacia fines de marzo. La temperatura media anual varía entre $23,5^{\circ} \mathrm{C}$ y $27,5^{\circ} \mathrm{C}$ con incremento de sur a norte. Los veranos son cálidos y húmedos (octubre a mayo) y los inviernos de menor temperatura y más secos, con presencia de vientos fríos provenientes del sur (surazos) que ocasionan serias dificultades, catastróficas para el universo biogeográfico.

El paisaje de Mojos en su conjunto presenta distintas formaciones vegetales, de estrecha incumbencia para la arqueología beniana, fundamentalmente sostenidas a partir del relieve y su composición pedológica.

1. Curiche y Bajios. Representados por lugares donde el agua permanece casi constantemente a expensas de zonas deprimidas. Este sector desarrolla vegetación constituida por plantas flotantes y pastos altos.

2. Pajonal. Sector caracterizado por inundaciones estacionales (de 5 a 6 meses), donde el agua muchas veces se retira por evaporación. Presenta vegetación herbácea de pastizales altos y densos, constituyendo actualmente las áreas de explotación ganadera en tiempos secos y en el pasado inmediato zona de explotación agrícola tal cual lo demuestran los vestigios arqueológicos denominados en general "obras de tierra".

3. Arboleda. Sector caracterizado por el desarrollo de inundaciones breves y presencia de matorrales abiertos. En regiones localizadas se observan extensos palmares.

4. Selva en Galería e Islas. Sector que corresponde a terrenos más altos, con buen drenaje, implantación de vegetación arbórea y suelos de buen potencial nutricional. Esta formación puede ser subagrupada en categorías menores de uso regional, en relación con la génesis de su relieve. a) Monte: selva en galería marginal; b) Montaña: selva en galería asentada en antiguos cauces; c) Isla: formación menor de iguales características generales pero acotada a superficies restringidas. Este sector, selva en galería e islas, representó, desde los primeros tiempos, el territorio utilizado por aborígenes y criollos para asentamiento y tareas agrícolas en parcelas denominadas chaco que abarcan superficies menores a 6 hectáreas, utilizables por períodos que no superan los 3 años por agotamiento del suelo. Luego el chaco queda en barbecho por un lapso de entre 6 a 8 años. El sistema de cultivo responde al denominado de roza y quema. Además este sector involucra las mayores alturas regionales y asegura resguardo de las inundaciones.

\section{El Beni de Nordenskiöld}

Las características de los antiguos habitantes, sus modos de asentamiento (montículos) y otras estructuras de tierra vinculadas a la agricultura (canales, pequeños túmulos, campos de camellones) o a la intercomunicación regional (calzadas) y la calidad y variedad de restos culturales que allí se manifestaban llamaron la atención de numerosos investigadores quienes, desde principios del siglo XIX a la fecha, produjeron contribuciones de distinto carácter, en función de la problemática que involucra a un área tan amplia (Nordenskiöld, 1916; Métraux, 1946; Denevan, 1962/63/66; Plafker, 1963; Erickson y Faldin, 1978; Faldin, 1984; Dougherty y Calandra, 1984; Erickson, 1980/88; Erickson y Candler, 1989; Mann, 2000).

Entre los años 1908/09 Nordenskiöld, realizó investigaciones en los Llanos de Mojos habiendo propuesto a la región como un verdadero interrogante arqueológico (Nordenskiöld, 1910; 1913; 1917; 1924). Fundamentalmente su labor investigativa fue llevada a cabo en relación de dependencia con la Misión Sueca Chaco-Cordillera y consistió en la ejecución de exploraciones antropológicas en sentido amplio, que en la República de Bolivia abarcaron territorios subandino, del chaco ${ }^{4}$ y amazónico. En el actual Departamento del Beni, en cercanías de su capital la ciudad de Trinidad, área correspondiente al Mojos Central, al oeste del río Mamoré, practicó excavaciones arqueológicas en los "mounds" Hernmarck, Macisito y Velarde determinando la existencia de abundantes restos arqueológicos, fundamentalmente cerámicos, depositados en "lomas artificiales", de distinto volumen, generalmente rodeadas de una zanja y vinculadas a otras estructuras similares producto del movimiento de grandes masas de tierra afectadas a funciones ya referidas. En la detallada comunicación publicada en 1913, describe los trabajos ejecutados, interpretaciones de los mismos, ilustraciones de las piezas halladas y un mapa de la región de las tierras bajas de Bolivia, con indicación de los principales rasgos fisiográficos, localidades de mayor jerarquía, ruta seguida por el autor, ubicación de los grupos etnográficos y de los sitios arqueológicos trabajados.

\section{Estado actual de la problemática}

Las investigaciones realizadas demuestran la existencia en los Llanos de Mojos de diferentes variantes culturales tanto en espacio como en tiempo, conformando hoy un panorama más complejo que aquel que reconociera y diera a conocer Nordenskiöld.

Las diferentes formas que emplearon los antiguos habitantes de la región respecto de la utilización del medio ambiente y de las modalidades de asentamiento se reflejan en su ergología, dejando entrever diferentes tendencias culturales. Los tres principales sectores ecológico-culturales de los Llanos de Mojos (Figura 1) establecidos en concordancia con la información hasta ahora disponible son:

${ }^{4}$ Es dable destacar que se debe también a la Misión Sueca el aporte de los primeros datos bioantropológicos sobre etnias de esta región (Méndez et al., 2001) 


\section{ACTA AMAZONICA}

\section{Oeste de Mojos (Cuenca del Río Beni)}

En las últimas investigaciones realizadas a lo largo del río Beni, entre las localidades de Rurrenabaque (Dto. del Beni, Pcia. de Ballivian) y Riberalta (Dto. del Beni, Pcia. de Vaca Diez), abordando el territorio firme desde el agua, se localizaron 11 sitios arqueológicos de los cuales sólo 7 han sido analizados a través de los materiales encontrados. En términos generales, este amplio sector comprende dos paisajes predominantes: sabana inundable y selva profusa. Esta última se origina a partir de prolongaciones de la Hylaea Amazónica que circunda a los Llanos por el norte, el este y en parte por el oeste, confundiéndose con las Yungas de La Paz y, hacia el sur, con las Yungas de Cochabamba. La caracterización de los sitios arqueológicos es una combinación, adecuada a cada ambiente, de la descripta para los otros dos sectores de los Llanos, aunque estos sitios de asentamiento nunca alcanzan proporciones tan

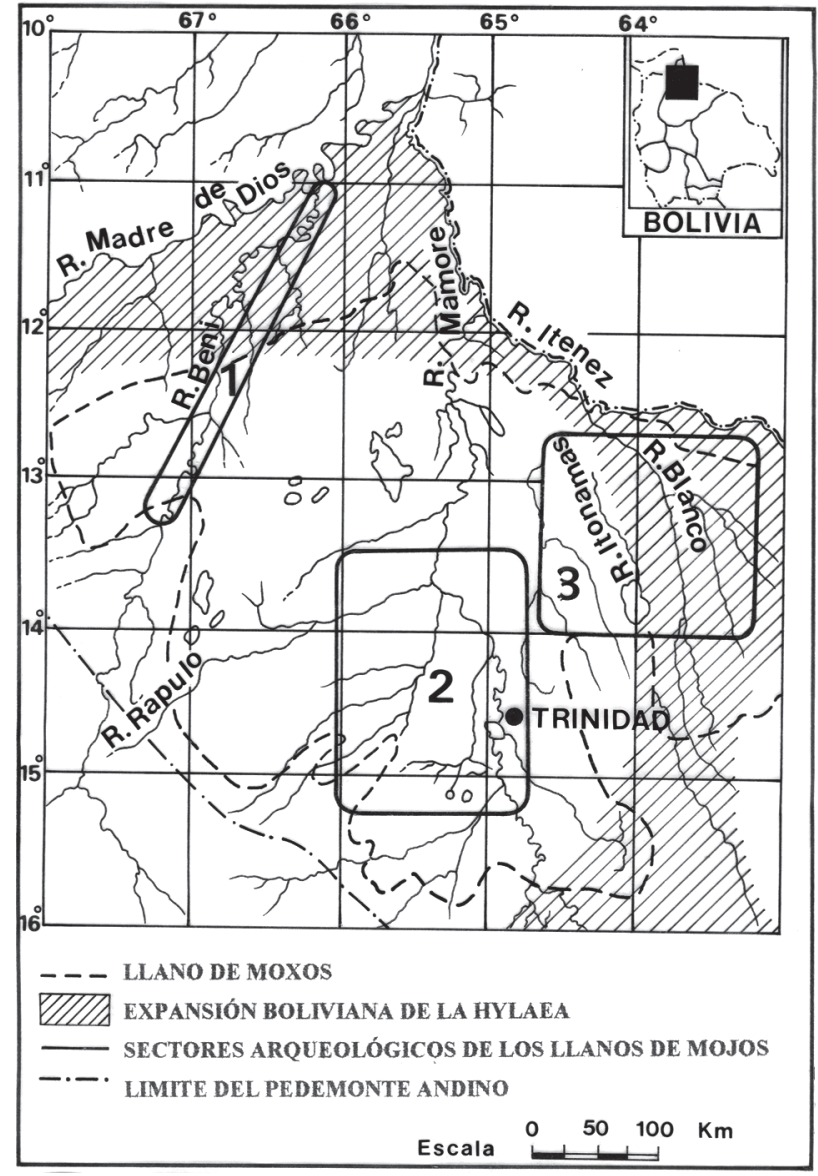

Figura 1 - Mapa de localización de los Sectores mencionados en el texto: 1. Oeste de Mojos (Cuenca del Río Beni); 2. Mojos Central; 3. Este de Mojos (Iténez) destacadas como los del sector central. Tampoco las antiguas estructuras vinculadas a la actividad agrícola tienen fuerte presencia. En la zona del Alto Río Beni, en las proximidades de Rurrenabaque, se individualizaron restos cerámicos novedosos, pero no sorprendentes, consistentes en piezas fragmentadas de alfarería incaica en sus motivos y morfología más caracterizantes ${ }^{5}$. De allí hacia el interior de los Llanos, en plena sabana de inundación, se hallaron materiales cerámicos que se corresponden con los hallados en los Llanos Centrales, en tanto que en la desembocadura del río Madre de Dios, la alfarería y la resolución constructiva de los asentamientos arqueológicos se asemeja a la hallada en el sector Iténez norte, zona donde también la Hylaea se dispone profusamente.

\section{Mojos Central.}

Abarca el territorio delimitado por los paralelos $13^{\circ} 30^{\prime}$ y $15^{\circ} 30^{\prime}$ de latitud sur y los meridianos 64 $30^{\prime}$ y $66^{\circ} 30^{\prime}$ de longitud oeste, ámbito en el cual se han reconocido y excavado más de 20 sitios arqueológicos emplazados en lomas ribereñas o en islas de sabana. En proximidades de la ciudad de Trinidad se excavaron dos de las lomas más importantes: Kiusiú y Mary que evidencian largas secuencias de ocupación.

Kiusiú está ubicada $5 \mathrm{~km}$ al oeste del río Mamoré y su datación arrojó una cronología absoluta que abarca entre el 550 d.C. y el 1200 d.C. Aparece como una loma mixta, es decir, de crecimiento debido tanto a procesos naturales como a actividades antrópicas. Loma Mary, hoy desaparecida por el desplazamiento natural del cauce del río Mamoré, estaba ubicada en una antigua margen, próxima a Puerto Varador. La cronología absoluta de ocupación abarca el período comprendido entre los años 245 d.C. y 1310 d.C. Ambos sitios, como tantos otros de zonas vecinas (lomas Palmasola, Suárez y Chuchini) son también "lomas mixtas".

Hacia el oeste del río Mamoré, los antiguos asentamientos se emplazan en "islas". Las excavaciones allí realizadas brindaron importante información acerca de superposiciones culturales. Generalmente estas islas presentan a su alrededor una zanja protectora, a veces complementada con una empalizada.

Hacia el este del Mamoré se manifiestan lomas cuya altitud varía entre $4 \mathrm{~m}$ y $16 \mathrm{~m}$, representando una excepción aquella mencionada por Denevan al S-SE de Loreto, denominada Cotoca, que alcanzaría una altura de $35 \mathrm{~m}$. Entre las más prominentes excavadas se destacan Loma Salvatierra con una asignación radiocarbónica entre 500 d.C. y 1200 d.C. (Dougherty y Calandra, 1981-82) y la Loma Alta de Casarabe (Rydén, 1941; Hanke, 1957; Denevan, 1966; Bustos, 1976a y b; Dougherty y Calandra, op. cit.).

\footnotetext{
${ }^{5}$ De acuerdo a los datos más recientes Raffino detecta caminos que partiendo de instalaciones incaicas emplazadas en zonas periféricas a las tierras bajas se internan en este ámbito. De esta manera toma mayor significación aquella de Rurrenabaque aludida en su oportunidad por Dougherty y Calandra representando, en aquel entonces, un posible hito fronterizo. Tal vez este juego de suposiciones, ávidas de estudios más sistematizados, permitirían sumar aquel criterio planteado por Cardich (1980) para fundamentar las fluctuaciones de los niveles cultivables.

${ }^{6}$ Mann malinterpretó lo vertido por Dougherty y Calandra respecto a la constitución de estas Lomas.
} 


\section{ACTA AMAZONICA}

La Loma Alta de Casarabe presenta una base de $600 \mathrm{~m}$ por $400 \mathrm{~m}$ y una altura de $16 \mathrm{~m}$. La excavación realizada pone de manifiesto la presencia de entre 22 y 32 ocupaciones superpuestas hasta una profundidad de $10 \mathrm{~m}$, abarcando un período entre los años 300 d.C. y 1200 d.C.

La alfarería del Mojos Central (Figura 2), en sus aspectos generales, se caracteriza por la utilización de antiplástico de tiesto molido; escasa presencia de cauixi y de conchilla (sólo a partir del 1000 d.C.); grandes platos discoidales, levemente cóncavos, con estrías paralelas y cruzadas (ralladores); manos fusiformes de arcilla con estrías o decoración puntiforme incisa; frecuencia elevada de piezas con patas trípodes y, en menor proporción, tetrápodas; pedestales altos; trozos de barro batido, tal vez de paredes; soportes para apoyar piezas sobre el fuego; hachas de piedra con garganta y con aleta; tembetás de hueso; puntas de proyectil hechas sobre diáfisis de huesos largos biseladas. La naturaleza de los suelos, ya aludida, plantea hallazgos incompletos de inhumaciones humanas bajo distintas modalidades tales como: extendido decúbito dorsal, con

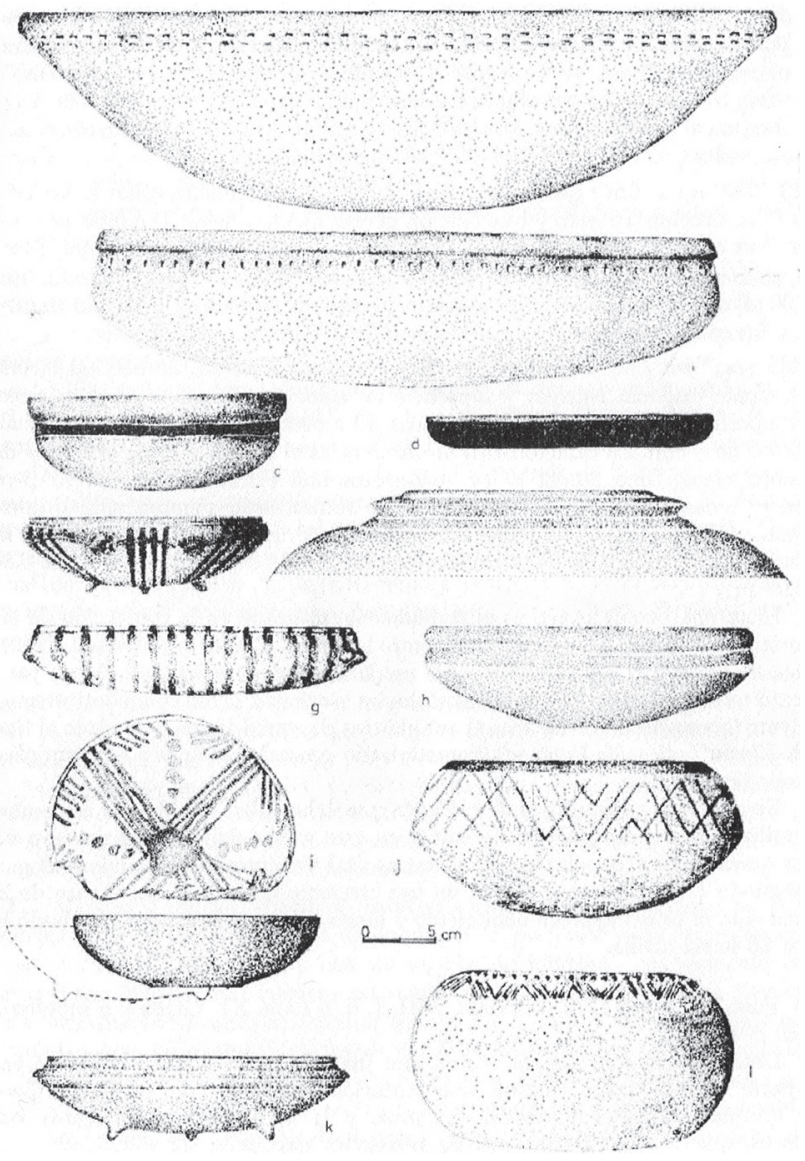

Figura 2 - Sector Central de Mojos. Algunas formas de las Fases Casarabe y Mamoré. escaso ajuar y, para etapas más recientes, cuerpos flexionados cubiertos con grandes platos o depositados en grandes vasijas campaniformes y entierros secundarios en vasijas ovoidales no citados para Mojos etnográfico.

\section{Este de Mojos (Iténez).}

En este ámbito, las características de los lugares en los cuales se han asentado los antiguos pobladores, también involucran a albardones ribereños, selvas marginales e islas. Sin embargo existen notorias y distintas características litológicas y ecológicas que acaso reflejen drásticas diferencias en los patrones de asentamiento aborígen pre y posthispánico.

Fueron localizados 20 yacimientos y se prospectaron 20 islas, de las cuales 5 produjeron restos arqueológicos (Dougherty y Calandra, 1984/85). Salvo el sitio denominado Bella Vista, ubicado en la unión de los ríos San Joaquín con el Blanco y el San Martín, en el extremo noreste de Bolivia, todos los demás son unicomponentes, de poca potencia y por encima de los $0,80 \mathrm{~m}$ de profundidad. La densidad areal de cerámica es baja y no han sido relevadas antiguas estructuras utilizadas para ejecutar agricultura de inundación, tal como se presentan en la zona central con tan alta frecuencia.

Tampoco se detectan lomas y la evidencia de sitios arqueológicos es fortuita, sobre todo a partir de áreas de desmonte afectadas a chacos. El indicador observable que evidencia la presencia de sitios arqueológicos lo constituyen zanjas anchas y profundas, circulares o elípticas, de $2 \mathrm{~m}$ a $5 \mathrm{~m}$ de profundidad y $4 \mathrm{~m}$ a $10 \mathrm{~m}$ de ancho, asignándoselas, en términos de la historia oral, a tiempos prehistóricos o históricos. Su finalidad es delimitar y aislar zonas, de 10ha aproximadamente, dentro de cuyo perímetro se emplazaban aldeas. Respecto de su función y dimensiones hay referencias escritas por parte de Nordenskiöld (1917) Métraux (1946) y Denevan (1966).

Otra estructura que se manifiesta en este sector, aunque con baja frecuencia respecto de su existencia en Mojos Central, son los canales lineales acompañados de terraplenes laterales, con un ancho aproximado de $2 \mathrm{~m} \mathrm{y}$, en la actualidad, con escasa profundidad (rellenos). Estos canales aun son utilizados como vías de navegación, fundamentalmente en tiempos de inundaciones, facilitando una comunicación rápida y directa, y formando una trama en toda la superficie de la sabana.

La alfarería del Noreste de Mojos (Figura 3) presenta predominio de antiplástico de cauixi y caolín y escasa presencia de desgrasante de tiesto molido; ausencia de ralladores y manos de moler; ausencia de apoyos para ollas (firedogs); escasa representación de patas complicadas; decoración predominante incisa (muy fina, fina y mediana) ${ }^{7}$, con escasa representación de aplicaciones y adornos y baja frecuencia de alfarería pintada, aunque atentos al mal estado de conservación de las superficies; sin registro de barro

\footnotetext{
${ }^{7}$ En varios yacimientos de la provincia de Iténez se ha obtenido alfarería con este tipo de decoración, con motivos lineales entrelazados de notoria similitud a otros hallados en Yurag Molino y Valle Ibirza
} 


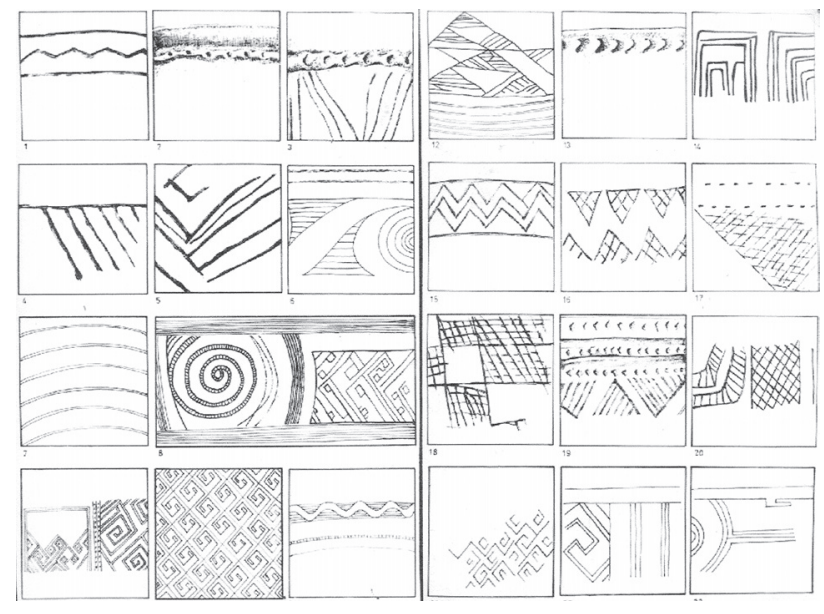

Figura 3 - Motivos decorativos del Sector Este de Mojos (Iténez).

batido o torta; inhumaciones humanas escasas, totalmente fragmentarias, en ocasiones identificables por trazas minerales. Sólo se halló un enterratorio (Bella Vista), en posición flexionado lateral, ubicado por debajo de una olla cilíndrica de gran diámetro colocada boca abajo. No cabe duda que el escaso contexto arqueológico conocido para Iténez permite entrever diferencias culturales respecto de los Llanos Centrales y una sospechosa inclinación hacia los tiempos históricos. Una correspondencia preliminar entre ambiente imperante, aspecto de la decoración y tipo y densidad del antiplástico, permitió segmentar a la región de Iténez en tres subsectores ecológico-culturales, presentando cada uno de ellos diferencias decorativas, siempre dentro de cánones generales comunes, y con variaciones sectoriales cuali y cuantitativas.

\section{DISCUSIÓN}

En el marco temporal considerado para los Llanos de Mojos, los rasgos caracterizantes de los distintos sectores y de ámbitos vecinos, si bien manifiestan aspectos diferenciales, todos se adscriben a las principales entidades culturales de presencia amazónica lo cual ineludiblemente implica fundamentar el grado de desarrollo cultural alcanzado y la densidad poblacional de los grupos humanos que allí habitaron. A este respecto se individualizan claramente dos posturas opuestas sostenidas por investigadores del más alto nivel científico e idoneidad en la temática (Meggers, 1997).

En las llanos de Mojos la manifiesta variabilidad cultural, su asignación témporo-espacial y la caracterización ecológica de la región Mojos no alcanzan aún para identificar la complejidad socio-política indicada para esta zona. Particularmente, la existencia de "obras de tierra" (Figura 4) de distinta morfología y resolución, aún no investigadas en todo su potencial y en situación de riesgo en función del incremento que toma día a día "la colonización" no planificada y sus consiguientes efectos catastróficos para el patrimonio natural y cultural, constituirían un elemento que alerta sobre la posible presencia de sociedades complejas.

A partir de la década del 60 la notable intensificación de apreciaciones sobre la existencia de estructuras de tierra en ámbitos de sabana permitió romper con un criterio previo que, basado en el elevado grado de acidez y dureza de los suelos y en la existencia anual de un largo período de inundación, aseguraba la inutilidad de estos terrenos para ser afectados a tareas agrícolas. El planteo despertó el interés de distintos investigadores, quienes comenzaron a proporcionar información sobre resoluciones constructivas similares para diversos territorios, como por ejemplo: orillas del Titicaca, Yucatán y Llanos de Venezuela. Estas estructuras constituyen estrategias constructivas para el control de agua en sistemas de agricultura en áreas inundables, vías de comunicación y lugares de asentamiento. En los Llanos de Mojos no han sido adscriptas con certeza a ningún período de tiempo o cultura en particular (Dougherty y Calandra, 1984). Su cronología relativa en el continente americano es variable (América Indígena, 1980; Denevan, 1980; Erickson, 1980). Denevan (1966 y com. pers.) se inclina a considerar su perduración hasta el siglo XVIII, aunque llama la atención la escasez de documentos en que testigos presenciales describan el funcionamiento de estos sistemas, lo cual permite suponer que constituirían "formas supérstites de épocas anteriores, en las que el cultivo con control de inundación hubiera revestido mayor importancia" (Dougherty y Calandra, 1984/85).

El ítem cerámico, uno de los elementos de mejor representación en los contextos ergológicos mojeños, permitió que casi la totalidad de los autores que abordaran la región consideraran los estilos definidos por Nordenskiöld y generaran correlaciones y diferenciaciones cronológicas. Bennett (1936) refiriéndose a Masicito sugirió nexos con alfarerías occidentales, específicamente de grupos Arawak tardíos a partir de expansiones Caribe, tal como lo señalara Lathrap (1970). Es atinado considerar que su origen podría estar en el antecedente de la denominada Tradición Incisa y Punteada de Amazonia posiblemente con vinculaciones con la Tradición Barrancoide del Orinoco.

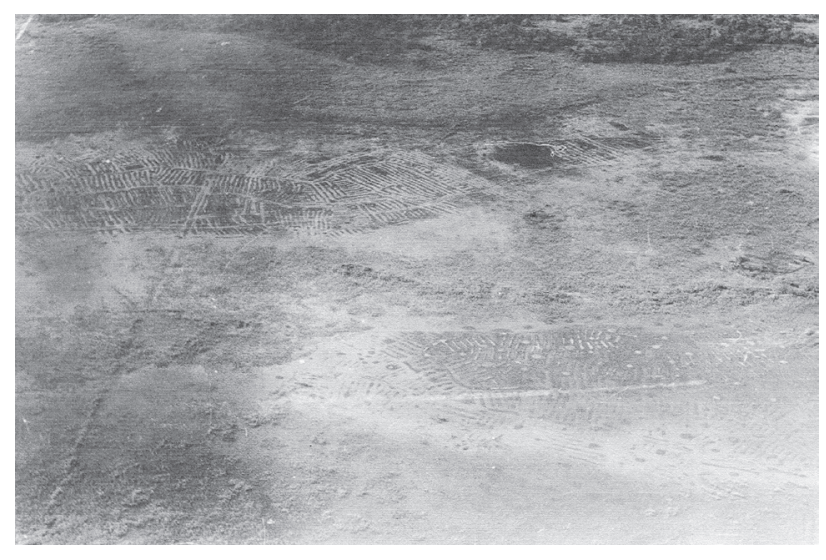

Figura 4 - "Obras de tierra". Vista aérea. 


\section{ACTA AMAZONICA}

En la Loma Alta de Casarabe (Departamento del Beni, Sector Central) se verificaron ciertas correlaciones con materiales de la Loma Masicito, de cronología inicial, equiparables con su fase más temprana o Fase Casarabe. También, aunque parcialmente, esta fase produjo materiales plausibles de cotejar con Bajo Velarde (Doughery y Calandra, 1981/82).

A Alto Velarde y Hernmarck se los asimila a la Tradición Polícroma de Amazonia (Bennett, 1936; Meggers y Evans, 1978). Alto Velarde no manifiesta aun una identificación clara con Tiahuanaco y Hernmarck, para algunos autores, sería más antiguo que Alto Velarde (Bennett, op. cit.) a pesar de la estrecha identidad entre los bienes ergológicos de ambos estilos. Los trabajos en Mojos Central (Dougherty y Calandra, op. cit.) insinúan la existencia de una Subtradición Polícroma Regional con caracteres particulares según ámbitos menores. Tal vez el desarrollo de investigaciones mas frecuentes e intensivas lleve a diluir esa separación entre Alto Velarde y Hernmarck.

Por último, Bajo Velarde, estilo que al decir de muchos es de definición confusa (Meggers y Evans, op.cit.) fue considerado por Howard (1947) como compartiendo rasgos con los demás estilos de Nordenskiöld. Este último autor hizo referencia a su posible vinculación con Tiahuanaco de Mizque, asociación que Bennett desechara por considerar que no estaban claros los criterios utilizados.

A estos estilos tradicionales se les sobreimponen cronológicamente, otras identidades culturales, aún no definitivamente establecidas, pero portadoras de cerámica con decoración pintada y fundamentalmente incisa muy fina, conformando motivos entrelazados. Rastrear su presencia en Mojos lleva a mirar desde el Ucayali (Lathrap, 1970) hasta el Guaporé (Becker Donner, 1956; Miller, 1992), hacia el norte, y en las proximidades de Santa Cruz de la Sierra (Riester, 1981), hacia el sur. Recientemente investigaciones realizadas en el Departamento de Cochabamba (Brockington et al., 2000) proveen información sobre la presencia de motivos similares en plena "área pedemontana", hallazgos que alertan acerca del sentido de su distribución espacial atentos al registro cronológico. Regionalmente en el territorio del Beni estas nuevas identidades culturales se recuestan con mayor presencia, en el sector este, en la provincia de Iténez, con diferentes cronologías relativas.

En síntesis, la poca información, fundamentalmente incompleta, en relación con la gran extensión territorial de los Llanos de Mojos, plantea que estamos en presencia de unámbito que aún necesita imperiosamente de la ejecución de investigaciones sistemáticas antropológicas en sus diferentes especialidades. En los sectores Central, Este y Oeste se desarrollaron secuencias preliminares chequeables, basadas principalmente en complejos cerámicos y formas de instalación. No obstante la destacada cantidad de información dada a conocer en los últimos años, en especial en estos sectores a los que aludiéramos, el resto del gran territorio plantea una incógnita que de no ser dilucidada con premura desaparecerán las condiciones de su estudio en función de la rápida transformación ecológica. Resulta indispensable y urgente abocarse a la problemática, en nuestro caso arqueológica, pues es imperioso saber con exactitud que papel le cupo a las tierras bajas bolivianas en el desarrollo y/o dispersión de rasgos culturales.
Respecto de una mayor antigüedad a la referida para la presencia de grupos humanos en el Beni, ésta podría ser inferida a partir del conocimiento que se tiene de su periferia, "...por la complejidad de las distribuciones lingüísticas y por la antigüedad de las estimaciones hechas para la diferenciación de troncos y familias lingüísticos" (Meggers y Evans, 1978).

Por último puede agregarse que una revisión de relatos y crónicas del momento de contacto hispano-indígena, permiten tener un panorama discreto acerca de la presencia y distribución de los grupos aborígenes refiriendo a aspectos tales como localización y características culturales. Los estudios etnohistóricos evidencian que esta región presentaba aspectos singulares de interés que llevaron a plantear asentamientos hispánicos permanentes tal vez en procura de riquezas y por encontrase allí densos asentamientos aborígenes. Algunos de estos establecimientos corresponden a las misiones jesuíticas mojeñas.

El hiatus o discontinuidad entre el hecho arqueológico y el etnográfico no está muy bien registrado en las crónicas. No cabe duda, como se ha manifestado, que es entonces cuando las "obras de tierra", las lomas, canales y sartenejas, sufren el embate del tiempo que sin misericordia las arrasa. Hoy el principal destructor es el mismo hombre que en pos de su "bienestar" avanza inexorablemente.

\section{AGRADECIMIENTOS}

Un especial reconocimiento a Héctor Díaz, amigo y técnico (CONICET-UNLP) y al Profesor Juan Faldín A., quienes participaron activamente de los trabajos de campo llevados a cabo en el Beni, registrando, documentando y asistiendo las excavaciones realizadas. Al Ing. R. Pinto Parada, Ing. H. Padilla, Sr. R. Bottega S., Sra. M. Lijerón, nuestro más cálido agradecimiento por sus oportunas sugerencias y dedicada gentileza.

\section{BIBLIOGRAFIA CITADA}

América Indígena. 1980. La agricultura intensiva prehispánica. Simposio del $43^{\circ}$ Congreso Internacional de Americanistas, Vancouver. América Indígena 40 (4).

Becker-Donner, E. 1956. Archäologische Funde am mittleren Guaporé (Brasilien). Archiv. für Völkerkunde, 11:202-249. Wien.

Bennet, W.C. !936. Excavations in Bolivia. Anthropological Papers American Mus. of Nat. His. 35 (4):329-507.

Braunstein, J.A.; Salceda, S.A.; Calandra, H.A.; Méndez, M.G.; Ferrarini, S.O. 2002. Historia de los Chaqueños - Buscando en la "papelera de reciclaje" de la Antropología Sudamericana. Acta Americana, Journal of the Swedish Americanist Society, 10 (1): 59-88.

Brockington, D.L.; Pereira Herrera, D.M.; Sanzetenea Rocha, R. 2000. Investigaciones arqueológicas en Sehuencas y Valle Ibirza de la zona tropical del Departamento de Cochabamba, Bolivia. In: Pereira Herrera, D.M.; Brockington, D.L. (Eds.) Investigaciones arqueológicas en las tierras tropicales del Departamento de Cochabamba, Bolivia. Universidad Mayor de San Simon, Cochabamba, Bolivia. p. 9-102. 


\section{ACTA AMAZONICA}

Bustos Santelices, V. 1976. (a) Excavaciones arqueológicas en Trinidad, Departamento del Beni. Instituto Nacional de Arqueología, Publicación No 22, La Paz.

Bustos Santelices, V. 1976 (b) Excavaciones arqueológicas en el sitio Grigotá (8011011), Santa Cruz. Instituto Nacional de Arqueología, Publicación No22, La Paz.

Calandra, H.A.; Dougherty, B. 1991. Prospección arqueológica en la provincia de Formosa, República Argentina. Hacia una nueva carta étnica del Gran Chaco (II): 133-141. Centro del Hombre Antiguo Chaqueño (CHACO). Formosa.

Cardich, A. 1980. El fenómeno de las fluctuaciones de los límites superiores del cultivo en los Andes: su importancia. Relaciones de la Sociedad Argentina de Antropología, 14 (1) N.S.:7-31. Buenos Aires.

Denevan, W.J. 1962. Informe preliminar sobre la geografía de los Llanos de Mojos, nordeste de Bolivia. Boletín Sociedad Geográfica e Histórica, Sucre, 47 (446): 91-113.

Denevan, W.J. 1963. Additional Comments on the Earthworks of Mojos in Northeastern Bolivia. American Antiquity, 28:540-545.

Denevan, W.J. 1966. The Aboriginal Cultural Geography of the Llanos de Mojos of Bolivia. Ibero-Americana, 48. Berkeley and Los Angeles; University of California Press.

Denevan, W.J. 1980. Prehispanic human settlement in the Llanos de Moxos. In: Rabasssa, J. (Ed.) Quaternary of South America and Antartic Peninsula 2: 163-199. Rotterdam, Balkema.

Dougherty, B.; Calandra, H.A. 1981/82. Excavaciones arqueológicas en la Loma Alta de Casarabe, Llanos de Moxos, Departamento del Beni, Bolivia. Relaciones de la Sociedad Argentina de Antropología, 14 (2) N.S.:9-48. Buenos Aires.

Dougherty, B.; Calandra, H.A. 1984. Pre-Hispanic human settlemen in the Llanos de Moxos, Bolivia. In: Rabassa, J. (Ed.) Quaternary of South America and Antartic Peninsula. 2: 162-169. Rotterdam, Balkema.

Dougherty, B.; Calandra, H.A. 1984/85. Ambiente y Arqueología en el Oriente Boliviano. La Provincia de Itenez del Departamento del Beni. Relaciones de la Sociedad Argentina de Antropología, Tomo XVI, Nueva Serie, pp 37-61.

Erickson, C.; Faldin, A.J. 1978. Preliminary Reports on an Archaeological Survey in the Llanos de Mojos, Bolivia: San Ignacio to San Borja. Paper presented at the Segunda Reunión de las Jornadas Peruano-Bolivianas Estudio Científico del Altiplano Boliviano y del Sur del Perú. Instituto Nacional de Arqueología, Documentos internos INAR No36/78.

Erickson, C. 1980. Sistemas agrícolas prehispánicos en los Llanos de Mojos. América Indígena, 40 (4):731-756.

Erickson, C. 1988. Raised field agriculture in the Lake Titicaca Basin. Expedition, Vol. 30 (3):8-16,

Erickson, C.; Candler, K. 1989. Raised fields and Sustainable Agriculture in the Lake Titicaca Basin of Perú. In: Broweder John O. Fragile Lands of Latin America: Estrategies for Sustainable Development, pp 230-248. Westview Press, Boulder, Co.,

Faldin, J.D. 1984. La arqueología beniana y su panorama interpretativo. Arqueología Boliviana No1: 83-90. La Paz, Bolivia.
Greenberg, J.H. 1956. The General Classification of the Central and South American Languages. Selected Papers of the Fifth International Congress of Anthropological and Ethnological Sciences. Philadelphia.

Hanke, W. 1957. Einige funde in Beni-Gebiet, Ostbolivien. Archiv für Völkerkunde (Wien), 12:136-143.

Howard, G.D. 1947. Prehistoric Ceramic Styles of Lowland South America. Their Distribution and History. Yale University Publications in Anthropology, N037. New Haven.

Lathrap, D.W. 1970. The Upper Amazon. Ancient Peolples and Places Collections. Thames \& Hudson. London.

Mann, Ch.C. 2000. Earthmovers of the Amazon. Science, New Focus, vol. 287: 786-789.

Meggers, B.J.; Evans, C. 1978. Lowland South America and the Antilles. In: Jennings, J.D. (Ed.), Ancient Native Americans, Chapter 12:543-591. San Francisco. Freeman.

Meggers, B.J. 1997. La Amazonía en vísperas del contacto europeo: perspectives etnohistóricas, ecológicas y antropológicas. In: Varón Gabai, R.; Flores Espinoza, J. (Eds.) Arqueología, Antropología e Historia de los Andes. Homenaje a María Rostworowski, p. 93113. Instituto de Estudios Peruanos. Lima, Perú.

Méndez, M.G.; Ferrarini, S.O.; Salceda, S.A.; Calandra, H.A. 2001. Bioantropología choroti: desde Eric Von Rosen hasta hoy. In: Universidad Nacional de Jujuy (Ed.) Un país más allá de las nubes (Seminario Internacional). A 100 años de la Expedición Sueca de Erland Nordenskiöld. p. 50-53.

Métraux, A. 1946. Tribes of Eastern Bolivia and the Madeira Headwaters. In: Steward, J.H. (Ed.) Handbook of South American Indian, vol 3:381-454. Bureau of American Ethnology Bulletin, 143. Smithsonian Institution,

Miller, E.T. 1992. Adaptaçao agrícola pré-histórica no alto río Madeira. In: Meggers, B. (Ed.) Prebistoria Sudamericana. Nuevas Perspectivas. Taraxacum:219-229. Washington.

Noble, G.K. 1965. Proto-Arawakan and its descendents. Indiana University Publications in Anthropology and Linguistics, 38.

Nordenskiöld, E. 1910. Archäologische Forschungen in bolivianischen Flachländen. Zeitschrift für Ethnologie (Berlin), 42: 806-822.

Nordenskiöld, E. 1913. Urnengräber und Mounds in Bolivianischen Flachlände. Baessler-Archiv (Leipzig und Berlin), 3:205-255.

Nordenskiöld, E. 1916. Die Anpassung der Indianer und die Verhältnisse in den Uberschwemmungsgebieten in Sudamerika. Ymer (Stockholm), 36: 138-155.

Nordenskiöld, E. 1917. Die östliche Ausbreitung der Tiahuanacokultur in Bolivien und ihr verhältnis zur Aruakkultur in Mojos. Zeitschrift fur Ethnologie (Berlin), 49: 10-20.

Nordenskiöld, E. 1924. Finds of graves and old dwelling-places on the rio Beni, Bolivia. Ymer (Stockholm), 44: 229-237.

Pereira Herrera, D.M.; Brockington, D.L. 2000. Introducción. In: Pereira Herrera, D.M.; Brockington, D.L. (Eds.) Investigaciones arqueológicas en las tierras tropicales del Departamento de Cochabamba, Bolivia. Universidad Mayor de San Simon, Cochabamba, Bolivia. p. 1-8.

Plaffker, G. 1963. Observations on Archaeological Remains in Northeastern Bolivia. American Antiquity, 38:372-378. 
Riester, J. 1981. Arqueología y arte rupreste en el oriente boliviano, Departamento de Santa Cruz. Editorial Los Amigos del Libro, 233 pp. Cochabamba, La Paz. Bolivia.

Rydén, S. 1941. A study of the Sirionó Indians. Göteborgs: Elanders Boktryckeri Aktiebolag. p. 167

Steward, J.H.; Faron, L.C. 1959. Native Peoples of South America. McGraw-Hill. New York.

\section{APENDICE}

Identificación de áreas y sitios arqueológicos prospectados y/o excavados en la Amazonia Boliviana (Años 1977/1981/1982) por Dougherty, B. y Calandra, H.

\section{Sector 1: Oeste de Mojos}

\section{Provincia Yacuma}

BE-YA- 1
BE-YA- 2
BE-YA- 3
BE-YA- 4
BE-YA- 5
BE-YA- 6
BE-YA- 7
BE-YA- 8
BE-YA- 9

Provincia Ballivián

BE-BA- 1

BE-BA- 2

BE-BA- 3

\section{Provincia Abel Iturralde}

LP-AT- 1
LP-AT- 2
LP-AT- 3
LP-AT- 4

Puerto Guzmán Chaco de Luis Castillo Puerto Villanueva Cachichira

\section{Provincia Madre de Dios}

PA-MA- 1

San Antonio

Sector 2: Mojos Central

\section{Provincia Cercado}

BE-CE- 7

BE-CE- 8

BE-CE- 9

BE-CE-10

BE-CE-11

BE-CE-12

BE-CE-13

BE-CE-14

BE-CE-15

BE-CE-16

BE-CE-17

\section{Provincia Mojos}

BE-MO- 1

BE-MO- 2

BE-MO- 3

BE-MO- 4

BE-MO- 5

BE-MO- 6

BE-MO- 7

BE-MO- 8

BE-MO- 9

\section{Provincia Marbán}

BE-MO- 1

Sector 3: Este de Mojos (Iténez)

Provincia lténez

BE-IT- 1

BE-IT- 2

BE-IT- 3

BE-IT- 4

BE-IT- 5

BE-IT- 6

BE-IT- 7

BE-IT- 8

BE-IT- 9

BE-IT-10

BE-IT-11

BE-IT-12

BE-IT-13

BE-IT-14

BE-IT-15

BE-IT-16

BE-IT-17
Naranjalito

La Belleza Loma de Peña Eviato

Loma Tokio Loma Carranza Loma Quevedo Loma Rica Habana

La Lomita San Carlitos

Loma Mary Empalme Loma Los Aceites Loma Dolores

Dos Islas El Puesto Totaizal II Loma Kiusiu Chaco de Arias

Chaco de Poño

Chalamama

Aserradero

Canabasneca

Nueva Calama La Cayoba Huacaraje (Equijebe) Bella Vista

La Cigarrera California

Chaco de Moreno Alta Gracia Irobi Baures San Ignacio San Calixto Buen Retiro Los Chuchíos
BE-CE- 1

BE-CE- 2

BE-CE- 3

BE-CE- 4

BE-CE- 5

BE-CE- 6
Loma Alta de Casarabe Loma Salvatierra San Juan de Agua Dulce Loma Chuchini Loma Suárez Loma Palmasola
RECEBIDO EM 27/02/2003

ACEITO EM 15/02/2004 
